\title{
Measurement of gastric emptying in infants with pyloric stenosis using applied potential tomography
}

\author{
S Nour, Y Mangnall, J A S Dickson, R Pearse, A G Johnson
}

\begin{abstract}
Gastric emptying in a group of 49 vomiting infants with infantile hypertrophic pyloric stenosis (IHPS) was investigated using applied potential tomography. Fourteen asymptomatic infants were also studied as a control group. A Dioralyte test feed ( $25 \mathrm{ml} / \mathrm{kg} /$ feed) was used for all the studies. The infants with IHPS were investigated before and at two, four, and seven days after an operation; the other infants were investigated once. The results show that the infants with IHPS have no or little gastric emptying before the operation and gradually return to normal emptying by the seventh day after the operation. A significant difference in gastric emptying was noted between the control infants and the infants with IHPS before and at two and four days after the operation.
\end{abstract}

The applied potential tomography method is suitable for studying gastric emptying in infants, with no morbidity nor complications. It also allows multiple studies to be performed without upset or discomfort.

(Arch Dis Child 1993; 68: 484-486)

Infantile hypertrophic pyloric stenosis (IHPS) which occurs in three of 1000 live births, ${ }^{1}$ is a common cause of vomiting in infants. Although the problem is corrected by pyloromyotomy some infants continue to vomit after the operation. There are a number of possible reasons for this, including persistent obstruction, abnormal gastric muscle electrical potentials, ${ }^{2}$ weakened lower oesophageal sphincter, ${ }^{3}$ atony of the stomach, ${ }^{4}$ or even coincidental gastro-oesophageal reflux. ${ }^{5}$

The aims of this study were to investigate the pathophysiological changes in infants with IHPS before and after pyloromyotomy, to assist in their clinical management, and to establish the gastric emptying pattern.

Approval of the local ethical committee was obtained. Written parental consent was also obtained on each occasion after a full oral and written explanation of the investigation.

The Children's Hospital, Western Bank, Sheffield S10 2TH

$S$ Nour

J A S Dickson

Royal Hallamshire Hospital, Sheffield Y Mangnall

A G Johnson

Jessop Hospital for Women, Sheffield R Pearse

Correspondence to: Dr Nour.

Accepted 15 November 1992 $(3700(100) \mathrm{g})$, and their ages ranged from 2 to 12 weeks $(5 \cdot 2(0 \cdot 1)$ weeks). Nine of these infants were born prematurely between 28 and 34 weeks' gestation (mean $32 \cdot 0$ weeks).
NORMAL (CONTROL) INFANTS

Fourteen asymptomatic infants (nine boys and five girls) were also investigated. Their birth weight ranged from 1740 to $3830 \mathrm{~g}(3100$ $(300) \mathrm{g})$, their weight at the time of investigation ranged from 2300 to $5500 \mathrm{~g}(4100(300) \mathrm{g})$, and their ages ranged from 2.5 to 11 weeks $(6 \cdot 3(0 \cdot 7)$ weeks). All infants were bottle fed. Two infants were born prematurely at 33 and 37 weeks' gestation; their postnatal ages were 11 and 6 weeks respectively.

\section{METHODS}

A detailed description of the applied potential tomography equipment and the method used has been published previously. ${ }^{6-8}$

Applied potential tomography is an electrically based method which creates tomographic images of tissue resistivity at an alternating current of $5 \mathrm{~mA}$ at $50 \mathrm{kHz}$ frequency.

For this study 16 electrodes were placed around the abdomen in the transpyloric plane. After a fasting recording of five minutes the infants were given a Dioralyte feed $(25 \mathrm{ml} / \mathrm{kg} /$ feed) containing sodium chloride $(5 \mathrm{mmol}$ added to $100 \mathrm{ml}$ feed) over a $15-20$ minute period. The applied potential tomography readings were taken at one minute intervals over a period of 70 minutes. After completion of the feed the infant was put in a sitting position to burp, and then laid in a cot in a supine position with a $10^{\circ}$ elevation of the left side of the body. In 22 studies the feed was introduced via a nasogastric tube, and by bottle in the remaining infants. All infants were fed over a similar period of time. It is probable that some of the feed emptied before the infant finished feeding.

At the end of the study period the stomach area was selected by recalling the first 10 frames after feed completion and outlined as the area of interest by a grid of pixels. Using the applied potential tomography analysis program the changes in resistivity for the gastric region were calculated and analysed for the whole study and a printout produced. Gastric emptying was considered to have started when the resistivity of the gastric region was higher (shown by a decrease on the graph) than that obtained immediately after feed completion for two or more consecutive readings.

To estimate the percentage of the meal remaining in the stomach at any time the applied potential tomography value at that time was expressed as a percentage of the maximum reading obtained after ingestion of the feed.

The time to half emptying of the feed $\left(T_{1 / 2}\right)$ corresponds to the return of the resistivity value to half of its maximum value after feed completion. 


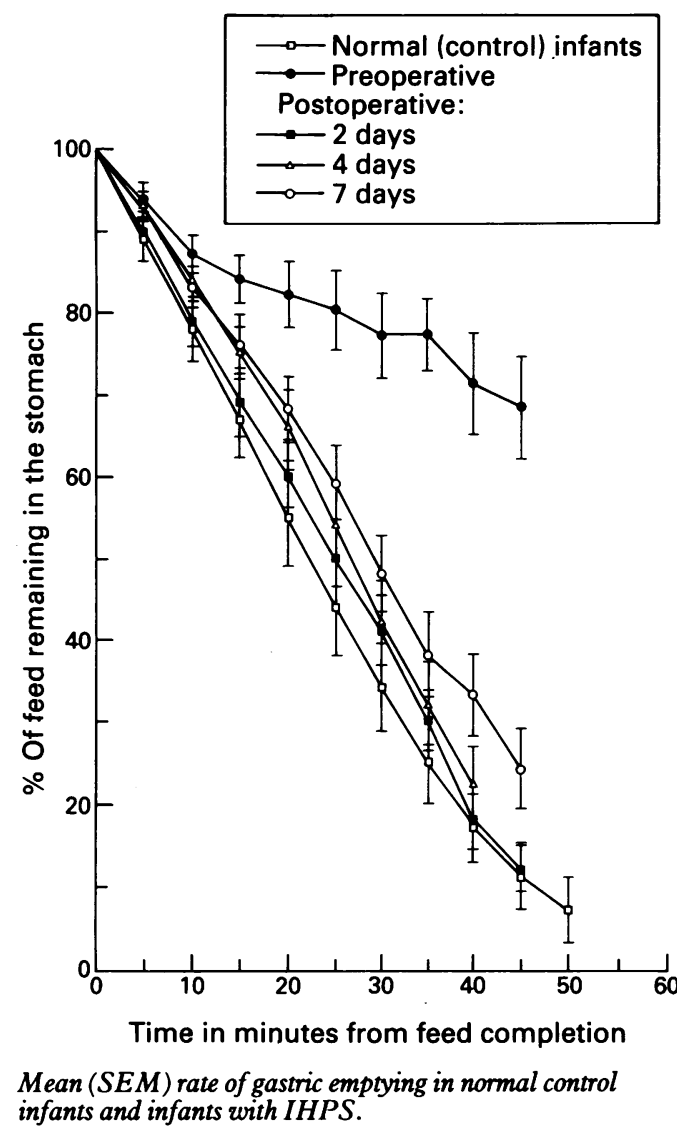

The nasogastric tube (when present) was aspirated at the end of the study and the volume recorded for validation.

\section{STATISTICS}

The Wilcoxon signed rank test was used to compare paired data between the infants with IHPS and the Mann-Whitney U test to compare the infants with IHPS with the normal and other vomiting infants. An abnormally slow or fast emptying result was defined as one that was more than 2 SD above or below the mean for the group of normal infants.

The infants with IHPS were studied before the operation ( 22 infants), then after the operation at days 2 (27 infants), 4 (24 infants), and 7 (27 infants), whereas the normal infants were studied by applied potential tomography once only. The numbers vary as not all infants were studied four times.

\section{Results}

All infants completed the investigation with no problems.

\section{NORMAL (CONTROL) INFANTS}

Gastric emptying was observed in all 14 infants. The time for half the feed to empty $\left(T_{1 / 2}\right)$ ranged from seven to 35 (mean (SD) $22 \cdot 0$ (6.9)) minutes.

\section{INFANTS WITH IHPS}

The studies before the operation ( 22 infants) showed no gastric emptying during the 70
Time taken for half the meal to empty $\left(\mathrm{T}_{1 / 2}\right)$ in control and infants with IHPS after the operation

\begin{tabular}{llcl}
\hline $\begin{array}{l}\text { Time after } \\
\text { operation }\end{array}$ & $\begin{array}{l}\text { Nowith } \\
\text { gastric } \\
\text { emptying }\end{array}$ & $\begin{array}{c}\mathrm{T}_{1 / 2} \text { range } \\
\text { (minutes) }\end{array}$ & $\begin{array}{l}\text { Mean }(S E M) \\
\mathrm{T}_{1 / 2}(\text { minutes })\end{array}$ \\
\hline Control $(\mathrm{n}=14)$ & 14 & $7-35$ & $22 \cdot 0(1 \cdot 8)$ \\
2 days $(\mathrm{n}=27)$ & 24 & $14-48$ & $31 \cdot 5(1 \cdot 7)$ \\
4 days $(\mathrm{n}=24)$ & 24 & $10-52$ & $30 \cdot 1(2 \cdot 0)$ \\
7 days $(\mathrm{n}=27)$ & 27 & $9-50$ & $27 \cdot 2(2 \cdot 0)$ \\
\hline
\end{tabular}

minute collection period in 13 infants, delayed gastric emptying in four infants (two infants emptied less than $10 \%$ of the feed by the end of the study; two infants had a delayed $T_{1 / 2}$ of 47 and 48 minutes), and five infants vomited (two some of the feed and three most of the feed). These results were validated by aspirating the nasogastric tube in 21 infants. There was close agreement (within 10\%) in the percentage of the feed remaining as determined by aspiration and by the change in resistivity in the area of interest shown by applied potential tomography in 17 infants. The remaining four infants showed an absolute difference of $25,28,32$, and $51 \%$. In these four infants the applied potential tomography results showed faster gastric emptying than the nasogastric tube.

One infant not included in these results continued to vomit after the operation and an applied potential tomography scan at four days after the operation showed complete obstruction; a gastric outlet obstruction caused by adhesion of the antrum to the pyloromyotomy site was relieved by a further operation. A repeat applied potential tomography study one week later showed normal gastric emptying with a $T_{1 / 2}$ of 27 minutes.

The studies at days 2,4 , and 7 after the operation showed a gradual improvement in gastric emptying (table and figure). At day 2, 24 of the 27 infants emptied the test feed; the other three infants did not empty any of the feed over the 70 minute study period and were still vomiting. At day 4 all 24 infants emptied the feed, including the three infants who had no gastric emptying at day 2. By day 7, 23 infants had normal gastric emptying and four had slow gastric emptying. A highly significant difference in $T_{1 / 2}$ was noted between normal infants and infants who had not yet had the operation $(\mathrm{p}<0.001)$. Applied potential tomography results at days 2 and 4 were still significantly different from the normal infants $(p<0.001$ and $\mathrm{p}<0.01$ respectively). By day 7 , however, there was no significant difference between the gastric emptying of infants with IHPS and normal infants.

\section{Discussion}

The changes in gastric emptying in infants with IHPS before and after pyloromyotomy have been successfully shown using applied potential tomography. Before the operation most infants with IHPS showed little or no gastric emptying and some vomited part or most of the feed, consistent with gastric outlet obstruction. Following pyloromyotomy the rate of gastric emptying gradually returned to normal by day 7; all 
infants emptied the meal and 23 of 27 had a normal rate of emptying. These results are similar to those obtained previously using barium meal ${ }^{910}$ or scintigraphy ${ }^{11}$; however, the rate of emptying was much slower than that shown by Lamont et al. ${ }^{12}$ These workers used applied potential tomography in a study of gastric emptying with a Dextrolyte feed before the operation in 11 infants with IHPS and found a slightly delayed gastric emptying in all infants ( $T_{1 / 2} 29-52$ minutes). In the present study the conductivity of the feed was increased by using Dioralyte with added sodium chloride, which improved the identification of the stomach image.

Applied potential tomography has a limited role in the diagnosis of IHPS as the pyloric test feed and ultrasound examination are simple and reliable. It could be helpful in investigating infants who continue to vomit after the operation, as illustrated by the infant who had continuous vomiting after pyloromyotomy.

Ultrasound does not assist in the management of these infants as it has been shown that the pyloric hypertrophy takes 2-12 weeks to resolve. ${ }^{13}$ Applied potential tomography has obvious advantages as it is non-invasive, painless, and can be repeated as often as required.

In conclusion, we found the applied potential tomography technique to be useful in investigating infants. This study has illustrated its potential for the study of gastric emptying. It is non-invasive, harmless, and can be used at the cot side with minimal disturbance.
This work was part of an MD thesis presented to the University of Sheffield, United Kingdom. The authors are grateful to the special trustees of the Old Sheffield United Hospitals for their generous financial support and to the CHRIS Fund which purchased the equipment.

We would like to thank Mr A E MacKinnon and Miss Jenny Walker, consultant paediatric surgeons at the Children's Hospital in Sheffield, who encouraged this study, and allowed us to study patients under their care.

1 Benson CD. Infantile hypertrophic pyloric stenosis. In: Welch KJ, Randolph JG, Ravitch MM, O'Neill JA Jr, Rowe MI, eds. Pediatric surgery. 4th ed. New York: Year Book Medical eds. Pediatric surgery. 4th

2 Scharli AF, Leditschke JF. Gastric motility after pyloromyotomy in infants: a reappraisal of post-operative feeding. Surgery 1968; 64: 1133-7.

3 She Y, Shen Z. Lower esophageal sphincter function in infantile hypertrophic pyloric stenosis. Pediatr Surg Int 1990; 5: 336-8. 4 Miller RF, Ostrum HW. Hypertrophic pyloric stenosis in Roentgenol 1945; 54: 17-29.

5 Forshall I. The cardiooesophageal syndrome in childhood. Arch Dis Child 1955; 30: 46-54.

6 Brown BH, Barber DC, Seagar AD. Applied potential tomography: possible clinical applications. Clin Phys Physiol Meas 1985; 6: 109-21.

7 Avill R, Mangnall YF, Bird NC, et al. Applied potential tomography - a new noninvasive technique for measuring gastric emptying. Gastroenterology 1987; 92: 1019-26.

8 Nour S, Mangnall Y, Dickson JAS, Johnson AG. Research of gastric emptying in infants using applied potential tomogastric emptying in infants using appled potential tomoworkshop. Ferrara: Universita Degli Studi Accademia Delle Scienze, 1992: 61-3.

9 LeWald LT. Roentgenologic examination of the digestive tracts of infants and children. Radiology 1933; $21: 221-9$.

10 Faber HK, Davis JH. Gastric perstalsis after pyloromyotomy in infants. FAMA 1940; 114: 847-50.

11 Signer E, Fridrich R. Gastric emptying in newborns and young infants. Acta Paediatr Scand 1975; 64: 525-30.

12 Lamont GL, Wright JW, Evans DF, Kapila L. An evaluation of applied potential tomography in the diagnosis of infantile hypertrophic pyloric stenosis. Clin Phys Physiol Meas 1988; 9: A65-9.

13 Okorie NM, Dickson JAS, Carver RA, Steiner GM. What happens to the pylorus after pyloromyotomy? Arch Dis Child 1988; 63: $1339-41$. 